\title{
Synthesis, Characterization and Catalytic Activity of MCM-41 Catalyst for Nitration of Phenol
}

\author{
SACHIN B. KAKODKAR \\ Department of Chemistry, Parvatibai Chowgule College of Arts and Science, \\ Margao - Goa, 403 602, India \\ sbk001@chowgules.ac.in
}

Received 18 September 2014 / Accepted 17 October 2014

\begin{abstract}
Synthesis of MCM-41 by various methods and their characterization by $\mathrm{x}$-ray diffraction and BET surface area has been discussed. The acid sites in the catalysts were estimated by temperature programmed desorption of ammonia. The catalytic activity of MCM-41 catalysts has been evaluated for the nitration of phenol. The catalytic activity is correlated to the acidity of the catalysts.
\end{abstract}

Keywords: MCM-41, Nitration, Phenol

\section{Introduction}

MCM-41, one member of the M41S family, possesses a regular hexagonal array of uniform pore openings with a broad spectrum of pore diameters between 15 and $100 \AA^{1,2}$. The mesoporous structure can be controlled by a sophisticated choice of templates, adding auxiliary organic chemicals and changing reaction parameters by varying temperature and compositions. MCM-41 materials are aluminosilicates with weak and middle-strength acid sites similar to amorphous silica-alumina. MCM-41 has been used as catalyst for various reactions such as dehydration $^{3}$, oxidation ${ }^{4}$, aldol condensation ${ }^{5}$, copolymerization ${ }^{6}$. The catalytic activity of MCM-41 for nitration of phenol has been reported and it is observed that acid sites in the catalyst are responsible for the activity ${ }^{7}$. The present paper deals with synthesis of MCM- 41 by various methods, their characterization evaluation of catalytic activity of these catalysts for the nitration of phenol. The catalytic activity is correlated to the acidity of the catalysts.

\section{Experimental}

The samples were synthesized as follows.

\section{SiMCM-41}

The silica MCM-41 was, synthesized by hydrothermal method using Aerosil 200 as a source of silica. The synthesis was carried out in an autoclave at $373 \mathrm{~K}$ for $72 \mathrm{~h}$. The $\mathrm{pH}$ was maintained in between 9.5 to 10 using $30 \%$ acetic acid solution. The final sample was washed 
with $2 \% \mathrm{HCl} / \mathrm{EtOH}$ solution, filtered, dried at $120{ }^{\circ} \mathrm{C} \mathrm{K}$ for $5 \mathrm{~h}$ and then calcined in air at $550{ }^{\circ} \mathrm{C}$ for $6 \mathrm{~h}$ to obtain SiMCM-41.

S/SiMCM-41(1)

A sulfated form of SiMCM-41 sample was prepared by wet impregnation method of using SiMCM-41(1). The sulfate ion was impregnated in the form of $\mathrm{H}_{2} \mathrm{SO}_{4} .5 \mathrm{~g}$ of SiMCM-41(1) was treated with $100 \mathrm{~mL}$ of $0.25 \mathrm{M} \mathrm{H}_{2} \mathrm{SO}_{4}$ at room temperature for $3 \mathrm{~h}$ and heated at $70{ }^{\circ} \mathrm{C}$ until complete dryness. The sample was dried at $120{ }^{\circ} \mathrm{C}$ for $2 \mathrm{~h}$ in an oven. The sample was then calcined in air at $550{ }^{\circ} \mathrm{C}$ for $12 \mathrm{~h}$ in a muffle furnace. The sample was designated as S/SiMCM-41(1).

S/SiMCM-41(2)

A sulfated form of SiMCM-41 sample was prepared by wet impregnation method of using SiMCM-41(1). The sulfate ion was impregnated in the form of $\mathrm{H}_{2} \mathrm{SO}_{4} .5 \mathrm{~g}$ of SiMCM-41(1) was treated with $200 \mathrm{~mL}$ of $0.25 \mathrm{M} \mathrm{H}_{2} \mathrm{SO}_{4}$ at room temperature for $3 \mathrm{~h}$ and heated at $70{ }^{\circ} \mathrm{C}$ until complete dryness. The sample was dried at $120{ }^{\circ} \mathrm{C}$ for $2 \mathrm{~h}$ in an oven. The sample was then calcined in air at $550{ }^{\circ} \mathrm{C}$ for $12 \mathrm{~h}$ in a muffle furnace. The sample was designated as S/SiMCM-41(2).

\section{AlMCM-41}

Aerosil 200 (Sisco Chem, India), 25 wt.\% aqueous solution of tetramethylammonium hydroxide (TMAOH), sodium aluminate (Fluka) and cetyltrimethylammonium bromide (CTMABr; Fluka) were used for the synthesis AlMCM-41. The hydrothermal synthesis was carried out by refluxing the magnetically stirred gel mixtures at atmospheric pressure. The sample was washed with water and dried at $120{ }^{\circ} \mathrm{C}$ and then calcined in air at $550{ }^{\circ} \mathrm{C}$ for $6 \mathrm{~h}$.

\section{HMCM-41(1)}

The HMCM-41(1) sample was prepared by exchange from AlMCM-41(1). $10 \mathrm{~g}$ of AlMCM41 was refluxed with $500 \mathrm{~mL}$ of $1 \mathrm{M}$ ammonium acetate solution thrice at room temperature to obtain the ammonium form. The ammonium form was then calcined in an air at $550{ }^{\circ} \mathrm{C}$ for $6 \mathrm{~h}$ to obtain the HMCM-41(1).

\section{NaMCM-41}

NaMCM-41 with a Si/Al ratio of 30 was synthesised using Aerosil 200 and aluminium sulphate as the silica and aluminium source, respectively. Cetyltrimethylammonium bromide was used as the template. The gel was autoclaved at $110{ }^{\circ} \mathrm{C}$ for $48 \mathrm{~h}$. The solid material obtained was filtered, washed with water and dried in the oven at $120{ }^{\circ} \mathrm{C}$. The resultant powder was calcined in air for $12 \mathrm{~h}$ at $550{ }^{\circ} \mathrm{C}$.

\section{HMCM-41(2)}

The NaMCM-41 sample was exchanged with $1 \mathrm{M}$ ammonium acetate solution. $10 \mathrm{~g}$ of NaMCM-41 was refluxed with $500 \mathrm{~mL}$ of $1 \mathrm{M}$ ammonium acetate solution thrice at room temperature to obtain the ammonium form. The ammonium form was then calcined in an air at $550{ }^{\circ} \mathrm{C}$ for $6 \mathrm{~h}$ to obtain the protonic form designated as HMCM-41(2).

\section{Characterisation of Catalysts}

$X$ ray diffraction

$\mathrm{X}$ ray diffraction studies were carried out on an ITAL STRUCTURES X ray diffractometer. 


\section{BET surface area measurements}

The BET surface areas of various catalysts were determined using a Smartsorb 91 surface area analyzer. The BET surface area of the various catalysts is shown in Table 1.

Table 1. Surface area of various catalysts

\begin{tabular}{lc}
\hline Catalyst & Surface Area, $\mathrm{m}^{2} / \mathrm{g}$ \\
\hline SiMCM-41 & 964 \\
S/SiMCM-41(1) & 832 \\
S/SiMCM-41(2) & 810 \\
AlMCM-41 & 886 \\
HMCM-41(1) & 793 \\
NaMCM-41 & 938 \\
HMCM-41(2) & 862 \\
\hline
\end{tabular}

\section{Acidity measurements}

Acidity of all the catalysts was measured using temperature programmed desorption (TPD) technique, using ammonia as a probe molecule. $100 \mathrm{mg}$ of a catalyst sample was packed in a catalytic reactor and activated in air at $500{ }^{\circ} \mathrm{C}$ for about 6 hours. The catalyst was then cooled to room temperature in flowing dry nitrogen. Anhydrous ammonia was passed over the catalyst for about 30 minutes for adsorption to occur. The sample was then heated at a rate of $5{ }^{\circ} \mathrm{C}$ per minute and the amount of ammonia desorbed as a function of temperature was calculated using titrimetry. The TPD profiles and the total acidity values of the catalysts are presented below (Figure $1 \&$ Table 2).

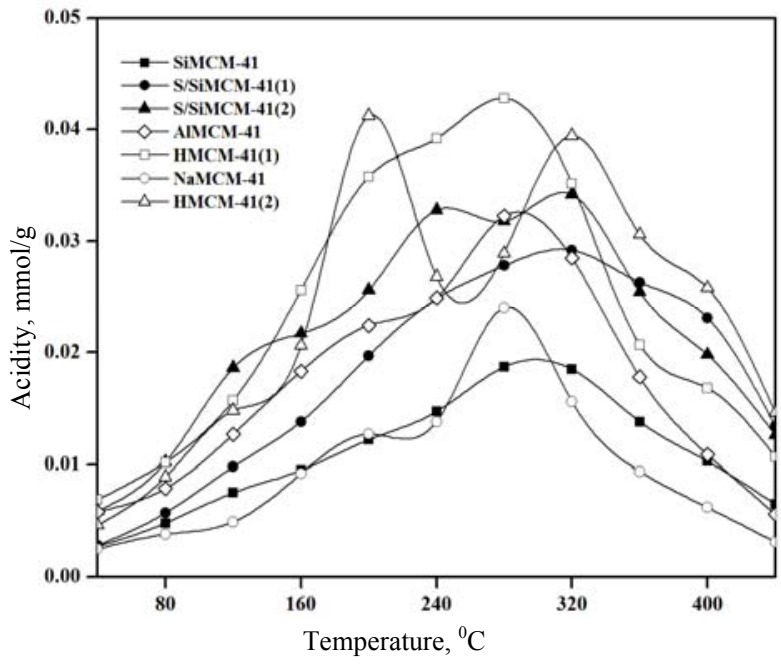

Figure 1 TPD profiles of various MCM-41 catalysts
Table 2. Total acidity of various MCM-41 catalysts

\begin{tabular}{lc}
\hline Catalyst & $\begin{array}{c}\text { Total Acidity, } \\
\mathrm{mmol} / \mathrm{g}\end{array}$ \\
\hline SiMCM-41 & 0.1192 \\
S/SiMCM-41(1) & 0.1964 \\
S/SiMCM-41(2) & 0.2386 \\
AlMCM-41 & 0.1871 \\
HMCM-41(1) & 0.2596 \\
NaMCM-41 & 0.1021 \\
HMCM-41(2) & 0.2416 \\
\hline
\end{tabular}

\section{Scheme 1}

Nitration of phenol

Nitration of phenol was carried out with equimolar ratio of phenol to nitric acid with MCM-41 catalysts (Scheme 1). Two millimole of phenol was taken in a two-necked round bottom flask containing $5 \mathrm{~mL}$ solvent (dichloro ethane) to which $0.100 \mathrm{~g}$ of catalyst and $2 \mathrm{mmol}$ of nitric acid (30 \%) were added. The reaction mixture was stirred at room temperature for $2 \mathrm{~h}$, filtered and then the reaction products were analyzed by using a Chemito 8610 HT gas chromatograph. 


\section{Results and Discussion}

The XRD pattern of SiMCM-41as seen from Figure 2 shows an absorption at an angle of $2 \theta=2.19^{\circ}$ which corresponds to the characteristic peak of SiMCM-41. AlMCM-41 also showed a similar pattern (Figure 3 ) confirming the synthesis of the two catalysts. The peaks at an angle of $2 \theta=4.14^{\circ}$ and $2 \theta=4.42^{\circ}$ indicate hexagonal geometry. Table 1 shows the surface areas of various MCM-41 catalysts. It can be seen that MCM-41 catalysts possess large surface areas. The surface areas decreased on sulphation of the catalyst. SiMCM-41 and NaMCM-41 samples exhibited very low total acidity. However acidity increased upon sulphation of the SiMCM-41 catalyst. Also proton exchange with $\mathrm{Na}$ of NaMCM-41 increased the acidity significantly. HMCM-41(1) synthesised from AlMCM-41 was the most acidic catalyst.

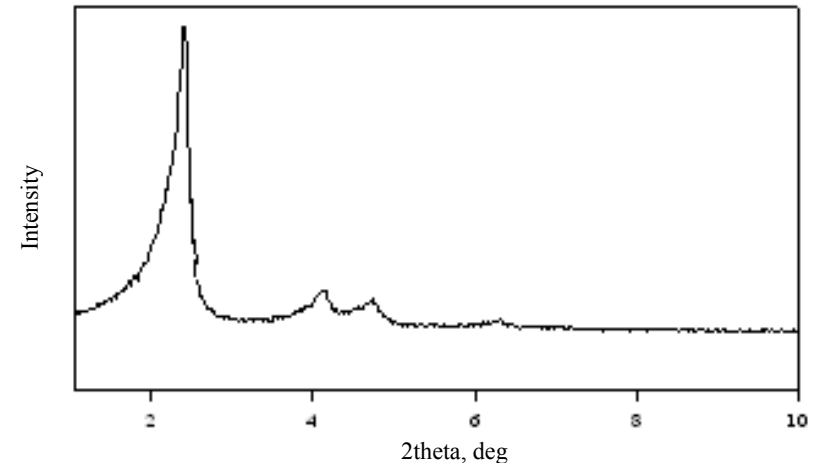

Figure 2. XRD pattern of SiMCM-41

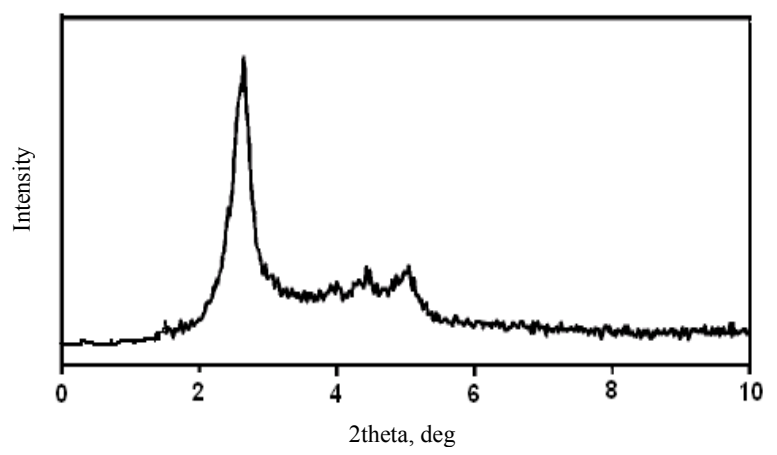

Figure 3. XRD pattern of AlMCM-41

For the nitration of phenol, the most acidic catalyst HMCM-41(1) showed the highest conversion of phenol. This proves that percentage conversion of phenol depends highly on the total acidity in the catalyst. The catalytic activity is enhanced upon sulphation of the catalyst. The effect of sulphation on catalytic activity for nitration of phenol over MCM-41 has been reported and it has been observed that increased sulphation favors higher catalytic activity ${ }^{7}$. Also the significant improvement of the catalytic activity upon sulphation of the catalyst that increased the acidity indicates that the reaction is favored by acidic sites. However a close look at the selectivity shows that HMCM-41(2) exhibited the highest selectivity towards the ortho product. Thus it is the most selective catalyst for the formation of $o$-nitrophenol. A comparison of catalytic activity of the two protonic samples shows that the more acidic catalyst resulted in 
a loss of selectivity towards the ortho product formation (Figure 4). This indicates that all the acid sites may not be used for the formation of ortho product. A fraction of sites may be active for this reaction. Thus the catalyst HMCM-41(2) which may possess a higher proportion of these sites is the most selective catalyst for the formation of $o$-nitrophenol.

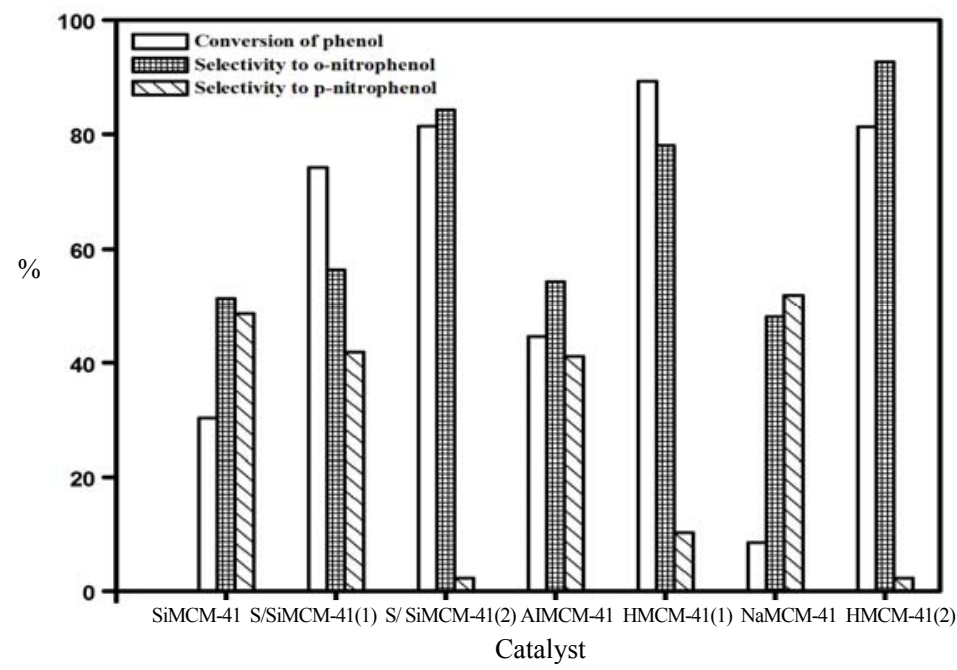

Figure 4. Catalytic activity of various MCM-41 catalysts

\section{Conclusion}

The catalyst with highest total acidity, viz.HMCM-41(1) shows maximum conversion of phenol whereas HMCM-41(2) shows highest selectivity towards the ortho product. The acid sites in the catalyst are the active sites for the catalytic activity of MCM-41 catalysts for nitration of phenol. However all the acid sites are not useful for selective formation of o-nitrophenol. Thus HMCM-41(2) which may possess a higher proportion of such sites shows highest selectivity towards the ortho product.

\section{Acknowledgement}

The author is thankful to University Grants Commission (New Delhi) for financial support.

\section{References}

1. Kresge C T, Leonowicz M E, Roth W J, Vartuli J C and Beck J S, Nature, 1992, 359(6397), 710; DOI:10.1038/359710a0

2. Beck J S, Vartuli J C, Roth W J, Leonowicz M E, Kresge C T, Schmitt K D, Chu C T W, Olson D H, Sheppard E W, McCullen S B, Higgins J B and Schlenker J L, J Am Chem Soc., 1992, 114(27), 10834-10843; DOI:10.1021/ja00053a020

3. Aquino J M F B, Souza C D R and Araujo A S, Int J Inorg Mater., 2001, 3(6), 467470; DOI:10.1016/S1466-6049(01)00042-3

4. Araujo R S, Costa F S, Maia D A S, Sant Ana H B and Cavalcante Jr C L, Braz J Chem Engg., 2007, 24(1), 135-141; DOI:10.1590/S0104-66322007000100012.

5. Kloetstra K R and Bekkum van H, J Chem Soc Chem Commun., 1995, 1005-1006; DOI:10.1039/C39950001005

6. Jiamwijitkul S, Jongsomjit B and Praserthdam P, Iran Polym J., 2007, 16(8), 549-559.

7. $\quad$ Parida K M and Rath D, J Molecular Cataly A: Chem., 2006, 258(1-2), 381-387; DOI:10.1016/j.molcata.2006.07.039 